\title{
Effect of solute and matric potential on growth rate of fungal species isolated from cheese
}

\author{
Patricia Marín , Daniel Palmero , Miguel Jurado
}

\begin{abstract}
A B S T R A C T
The effect of water potential $\left(\Psi_{\mathrm{w}}\right)$ on the growth of 15 fungal species isolated from cheeses was analysed. The species, identified mainly by analysis of DNA sequences, belonged to genera Penicillium, Geotrichum, Mucor, Aspergillus, Microascus and Talaromyces. Particularly, the effect of matric potential $\left(\Psi_{\mathrm{m}}\right)$, and ionic $(\mathrm{NaCl})$ and non-ionic (glycerol) solute potentials $\left(\Psi_{s}\right)$ on growth rate was studied. The response of strains was highly dependent on the type of $\Psi_{\mathrm{w}}$. For $\Psi_{\mathrm{s}}$, clear profiles for optimal, permissive and marginal conditions for growth were obtained, and differences in growth rate were achieved comparing $\mathrm{NaCl}$ and glycerol for most of the species. Conversely, a sustained growth was obtained for $\Psi_{\mathrm{m}}$ in all the strains, with the exception of Aspergillus pseudoglaucus, whose growth increased proportionally to the level of water stress. Our results might help to understand the impact of environmental factors on the ecophysiology and dynamics of fungal populations associated to cheeses.
\end{abstract}

\section{Introduction}

Moulds play a determinant role on quality of cheeses. The presence of some species might be necessary for the development of a particular appearance, and rheological and sensory characteristics. Such is the case of blue veined cheeses (e.g., Roquefort) and surface mould-ripened cheeses (e.g., Camembert), where Penicillium roqueforti and Penicillium camemberti, respectively, contribute to the formation of texture and flavour through the action of its protease and lipase systems (Larsen \& Jensen, 1999; Le Dréan et al., 2010). However, uncontrolled growth of filamentous fungi during ripening of cheeses may cause undesirable effects that include offflavours, anomalous textures, discolourations and accumulation of mycotoxins (Sengun, Yaman, \& Gonul, 2008). For these reasons, there has been an increasing interest in analysing fungal populations associated with cheese over the last two decades (Erdogan, Gurses, \& Sert, 2003; Kure \& Skaar, 2000; Kure, Wasteson, Brendehaug, \& Skaar, 2001; Lund, Filtenborg, \& Frisvad, 1995; Montagna et al., 2004). More recently, important progress has been achieved with the use of molecular methods, which have improved the accuracy of identification, and have also allowed the determination of genetic variability and the description of new fungal populations and species (Flórez, Âlvarez-Martín, López-Díaz, \& Mayo, 2007; Hermet, Méheust, Mounier, Barbier, \& Jany, 2012; Pannelli, Buffoni, Bonacina, \& Feligini, 2012). However, it is generally considered that taxonomy of cheese fungi is still poorly understood (Ropars, Cruaud, Lacoste, \& Dupont, 2012) and, more importantly, the information available about the ecology and physiology of these species is very scarce.

One of the most critical environmental parameters that determine the growth of fungi in any substrate is water availability. The concept of water activity $\left(a_{w}\right)$ introduced by Scott (1957), has been widely used in food science literature to denote the total water content available for microorganisms, and is defined as the ratio of the vapour pressure of water in a material to the vapour pressure of pure water at the same temperature. Water availability can be alternatively expressed as water potential $\left(\Psi_{\mathrm{w}}\right)$, which is the potential energy of water per unit volume relative to pure water in reference conditions, and it is measured in pressure units of megapascals (MPa) or bars (Magan, 2007). $\Psi_{\mathrm{w}}$ gives a good estimate of water balance, since it can differentiate between the forces required to remove water bound to the food matrix, the matrix potential $\left(\Psi_{\mathrm{m}}\right)$, and the forces due to colligative effects of dissolved compounds, the osmotic or solute potential $\left(\Psi_{\mathrm{s}}\right)$ (Jurado, Marín, Magan, \& González-Jaén, 2008). 
To control the quality of cheese, it is therefore important to understand the effects that changes in water status might have on growth kinetics of moulds. The objectives of this study were to isolate and identify fungi from a wide variety of hard and soft cheeses and to evaluate and compare their growth rates under the effect of ionic and non-ionic $\Psi_{\mathrm{s}}$ and $\Psi_{\mathrm{m}}$.

\section{Material and methods}

\subsection{Isolation of moulds from cheese}

A total of 19 cheeses were purchased in local supermarkets in Spain during 2011 and 2012 , stored at $4{ }^{\circ} \mathrm{C}$, and analysed the day after collection. Samples included a wide variety of hard and soft cheeses made from cow, ewe, goat or mixed milk (Table 1). Ten small pieces from the surface layer of each cheese were excised under aseptic conditions, and directly plated onto 9-cm diameter Petri dishes containing $20 \mathrm{~mL}$ of oxytetracycline glucose chloramphenicol agar (Oxoid, Madrid, Spain). Plates were incubated aerobically in the darkness at $25{ }^{\circ} \mathrm{C}$ and observed daily. Colonies displaying different morphological characteristics were transferred to plates containing Sabouraud agar medium (Oxoid) to obtain monosporic cultures, and incubated at $25^{\circ} \mathrm{C}$ for 7 days. Isolates were maintained at $-20^{\circ} \mathrm{C}$ as spore suspensions in $15 \%(\mathrm{v} / \mathrm{v})$ glycerol.

\subsection{DNA extraction and $P C R$ amplification}

Genomic DNA extractions of fungal isolates were undertaken using three mycelium discs excised from 5- to 7-day-old Sabouraud plate cultures, and making use of the DNeasy Plant Mini Kit (Qiagen, Hilden, Germany) according to the manufacturer's instructions. DNA concentrations were determined using a NanoDrop ${ }^{\circledR}$ ND-1000 spectrophotometer (Nanodrop Technologies, Wilmington, DE, USA). The nuclear ribosomal internal transcribed spacer (ITS) region was amplified by PCR using the primers and protocol described elsewhere (White, Burns, Lee, \& Taylor, 1990). Amplification of the $\beta$-tubulin gene (TUB2) was performed using primers Bt2a and Bt2b according to Glass and Donaldson (1995). PCR-amplified fragments were purified using the UltraCleanTM PCR Clean-UpTM kit (MoBio Laboratories Inc., Carlsbad, CA, USA) according to the manufacturer's instructions, and sent for direct sequencing to STABVIDA ${ }^{(B)}$ (Caparica, Portugal). Automated sequencing of both strands was performed using the BigDye Terminator Kit by Applied Biosystems and the 96-capillary 3730xL DNA Analyzer by Applied Biosystems (Foster City, California, USA). The sequences were corrected using Chromas version 1.43 (Griffith University, Brisbane, Australia) and analysed and edited using Bioedit Sequence Alignment Editor version 7.0.9.0 (Hall, 1999). Sequences were deposited in the GenBank database, and numbers of accession are shown in Table 1.

\subsection{Identification of fungi}

Identification of fungi was based on the analysis of DNA sequences. Morphological and cultural observations were also done for isolates whose DNA sequences were uninformative. The keys developed by Frisvad and Samson (2004) were used for Penicillium isolates, whereas identification of isolates belonging to genus Aspergillus was done according to the keys developed by Hubka, Kolaric, Kubatova, and Peterson (2013).

\subsection{Growth in relation to $\Psi_{s}$ and $\Psi_{m}$}

Sabouraud dextrose broth (Oxoid) supplemented with $2 \%$ agar (Oxoid) was used in this study. The $\Psi_{\mathrm{s}}$ was modified with the ionic solute sodium chloride or the non-ionic solute glycerol to $-3.80,-7.72,-11.63$ and $-15.53 \mathrm{MPa}$ corresponding to $a_{\mathrm{w}}$ of $0.975,0.950,0.925$ and 0.900 , respectively. These solutes were not added to the control medium $\left(-0.7 \mathrm{MPa}=0.995 a_{\mathrm{w}}\right)$.

The $\Psi_{\mathrm{m}}$ media were modified with polyethylene glycol 8000 (PEG 8000) (Sigma, Madrid, Spain) to obtain treatments of $-3.80,-7.72,-11.63$ and $-15.53 \mathrm{MPa}$, respectively. PEG 8000 is known to act predominantly by matrix forces (Steuter, Mozafar, \& Goodin, 1981). For matrically modified treatments, the agar was omitted and sterile circular discs of capillary matting (Nortene; $8.5 \mathrm{~cm}$ in diameter, $2 \mathrm{~mm}$ thick) were used to provide support for fungal growth. The capillary matting was overlaid with sterile cellophane sheets (28NP; Natureflex, Burgos, Spain). The control medium was similarly prepared, except that PEG 8000 was omitted $\left(-0.7 \mathrm{MPa}=0.995 a_{\mathrm{w}}\right)$.

\subsection{Inoculation, incubation, and growth assessment}

A 5-mm-diameter agar disk from the margin of a 7-day-old growing colony of each isolate grown at $20^{\circ} \mathrm{C}$ was used to centrally inoculate each replicate and treatment. The plates were incubated at $20^{\circ} \mathrm{C}$ for 10 days, and the experiment consisted of a fully replicated set of treatments with three replicates per treatment. Assessment of growth was made daily during the 10-day incubation period. For each colony, the mean radial mycelial growth was calculated by measuring two different colony radii in each of the three plates per combination of isolate and $\Psi_{\mathrm{m}} / \Psi_{\mathrm{s}}$ treatment. The growth was corrected by subtracting the $5 \mathrm{~mm}$ diameter of the original plug of inoculum and plotted against time, and a linear regression was applied to obtain the growth rate as the slope of the line.

\subsection{Statistical analysis of results}

The linear regression of increase in radius against time $(d)$ was used to obtain growth rates $\left(\mathrm{mm} \mathrm{d}^{-1}\right)$ as indicated in 2.5 for each set of treatments. A two-way analysis of variance (ANOVA) of 'value of $\Psi_{\mathrm{w}}$ ' $(-0.7,-3.80,-7.72,-11.63$ and $-15.53 \mathrm{MPa}) \times$ 'type of $\Psi_{\mathrm{w}}$ ' ( $\mathrm{NaCl}$, glycerol or PEG 8000) was carried out for each fungal strain. A one-way ANOVA was performed when interaction of both factors ('value of $\Psi_{\mathrm{w}} \times$ type of $\Psi_{\mathrm{w}}$ ') was significant. Subsequent post hoc analyses (Tukey's HSD tests of multiple comparisons) were carried out at a $95 \%$ confidence level.

\section{Results}

\subsection{Identification of fungi}

A total of 30 isolates were obtained from the 19 samples of cheese analysed, and their respective ITS sequences are shown in Table 1 . The isolates belonged to 15 different species from genera Penicillium (16 isolates), Geotrichum (6 isolates), Mucor (4 isolates), Aspergillus (3 isolates), Microascus (1 isolate) and Talaromyces (1 isolate). Most of the isolates could be unambiguously identified by analysing exclusively the ITS sequence. However, morphological and cultural observations were necessary for identification of the species Penicillium solitum, Penicillium discolor, Aspergillus glaucus and Aspergillus pseudoglaucus, since they are known to carry identical ITS sequences to other species (Frisvad \& Samson, 2004; Hubka et al., 2013). In addition, identification of isolate Zam2 (Microascus manginii) was done based on the analysis of TUB2 sequence (number of accession KF298094), since no ITS amplification could be obtained with universal primers described by White et al. (1990). TUB2 sequence was also obtained for isolate Qpe3 (number of accession KF298093), but this strain could not be 
Table 1

Fungal species isolated from different varieties of cheese and respective accession numbers for their ITS (nuclear ribosomal internal transcribed spacer) sequences.

\begin{tabular}{|c|c|c|c|c|}
\hline Cheese $^{a}$ & Country of production & Isolate & Species $^{b}$ & $\begin{array}{l}\text { GenBank accession } \\
\text { number (ITS) }\end{array}$ \\
\hline \multirow[t]{2}{*}{ Mahón ${ }^{\mathrm{c}, \mathrm{h}}$} & Spain & Mah1 & Aspergillus varians* & KF298063 \\
\hline & & Mah2 & Geotrichum candidum & KF298068 \\
\hline Bettlematt ${ }^{\mathrm{c} ; \mathrm{h}}$ & Italy & Bet1 & Mucor racemosus* & KF298073 \\
\hline Bamalou ${ }^{\mathrm{c}, \mathrm{h}}$ & France & Bam1 & Mucor circinelloides* & KF298072 \\
\hline Majorero $^{\mathrm{g}: \mathrm{h}}$ & Spain & Maj1 & Penicillium discolor* & KF298079 \\
\hline \multirow[t]{3}{*}{ Ibores $^{g ; h}$} & Spain & Mon 1 & Penicillium roqueforti & KF298083 \\
\hline & & Mon2 & Penicillium solitum & KF298084 \\
\hline & & Mon3 & Mucor circinelloides & KF298075 \\
\hline \multirow[t]{3}{*}{ Zamorano $^{\mathrm{e}: \mathrm{h}}$} & Spain & Zam1 & Penicillium solitum ${ }^{*}$ & KF298091 \\
\hline & & Zam2 & Microascus manginit* & \\
\hline & & Zam3 & Penicillium chermesinum* & KF298090 \\
\hline \multirow[t]{3}{*}{ Castellano $^{\mathrm{e} ; \mathrm{h}}$} & Spain & Qpe1 & Penicillium chrysogenum* & KF298086 \\
\hline & & Qpe2 & Penicillium discolor & KF298087 \\
\hline & & Qpe3 & Penicillium spp.* & KF298088 \\
\hline Castellano $^{\mathrm{e} ; \mathrm{h}}$ & Spain & Bal1 & Penicillium solitum & KF298077 \\
\hline \multirow[t]{3}{*}{ Manchego $^{\mathrm{e} ; \mathrm{h}}$} & Spain & Man1-1 & Penicillium discolor & KF298080 \\
\hline & & Man1-2 & Talaromyces amestolkiae* & KF298092 \\
\hline & & Man1-3 & Penicillium roqueforti* & KF298081 \\
\hline Manchego ${ }^{\mathrm{e} / \mathrm{h}}$ & Spain & Man2-1 & Penicillium solitum & KF298082 \\
\hline \multirow[t]{2}{*}{ Manchego ${ }^{\mathrm{e} ; \mathrm{h}}$} & Spain & Man3-1 & Aspergillus glaucus* & KF298065 \\
\hline & & Man3-2 & Aspergillus pseudoglaucus* & KF298064 \\
\hline Oropesa $^{\mathrm{e} ; \mathrm{h}}$ & Spain & Oro1 & Penicillium discolor & KF298085 \\
\hline Tomette des Alpes ${ }^{c, g ; h}$ & France & Tom 1 & Geotrichum candidum & KF298071 \\
\hline Gamoneu ${ }^{c, g, e ; h}$ & Spain & Gam1 & Penicillium olsonii ${ }^{*}$ & KF298078 \\
\hline Thurgauer weinkäse ${ }^{c ; s}$ & Switzerland & Thu1 & Geotrichum candidum & KF298070 \\
\hline Arzúa-Ulloa ${ }^{c ; s}$ & Spain & Arz1 & Penicillium discolor & KF298076 \\
\hline \multirow[t]{2}{*}{ Fleur du maquis ${ }^{\mathrm{e} ; \mathrm{s}}$} & France & Fle1 & Geotrichum candidum & KF298066 \\
\hline & & Fle2 & Mucor racemosus & KF298074 \\
\hline Gour noirg;s & France & Gou1 & Geotrichum candidum & KF298067 \\
\hline Quesuco de Liébana ${ }^{\mathrm{c}, \mathrm{e}, \mathrm{g} ; \mathrm{s}}$ & Spain & Que1 & Geotrichum candidum ${ }^{*}$ & KF298069 \\
\hline
\end{tabular}

a Superscript letters indicate: c, cow milk cheese; g, goat milk cheese; e, ewe milk cheese; h, hard cheese; $s$, soft cheese.

${ }^{b}$ An asterisk indicates isolates used for evaluating growth in relation to solute potential $\left(\Psi_{\mathrm{s}}\right)$ and matric potential $\left(\Psi_{\mathrm{m}}\right)$.

ascribed to any known species on the basis of the analysis of DNA sequences (ITS or TUB2), nor by morphological or cultural studies.

\subsection{Fungal growth in relation to $\Psi_{s}$ and $\Psi_{m}$}

The results of the two-way ANOVA performed separately per each fungal strain showed significant interaction between 'value of $\Psi_{\mathrm{w}}$ ' and 'type of $\Psi_{\mathrm{w}}$ ' for all the strains tested (data not shown). Subsequently, one-way ANOVA and their correspondent Tukey's HSD tests were carried out to determine which values were statistically significant (Table 2).
Except for $M$. manginii, fungal growth was influenced by whether colonies were grown directly on the agar medium $\left(\Psi_{S}\right)$ or on cellophane overlays $\left(\Psi_{\mathrm{m}}\right)$. This was evidenced by the lower growth obtained for most of the isolates at $-0.7 \mathrm{MPa}$ (control) in the matrically modified media $\left(\Psi_{\mathrm{m}}\right)$ (Fig. 1 ), with the only exception of Aspergillus varians, that was able to grow faster on the cellophane-overlaid medium. Therefore, absolute values of growth rate could not be compared between $\Psi_{\mathrm{s}}$ and $\Psi_{\mathrm{m}}$ data sets. In any case, fungal growth profiles were very different depending on the type of $\Psi_{\mathrm{w}}$ considered. The notable influence of $\Psi_{s}$, which produced clear profiles for optimal, permissive and marginal

Table 2

Results of Tukey's HSD tests performed separately per fungal strain for growth rate (mm d $\left.{ }^{-1}\right)$ and carried out for value of water potential ( $\left.\Psi_{\mathrm{w}}\right)$ and type of $\Psi_{\mathrm{w}}{ }^{\mathrm{a}}$

\begin{tabular}{|c|c|c|c|c|c|c|c|c|}
\hline \multirow[t]{2}{*}{ Species and isolate } & \multicolumn{5}{|c|}{ Value of $\Psi_{\mathrm{w}}(\mathrm{NaCl} / \mathrm{Glycerol} / \mathrm{PEG} 8000)$} & \multicolumn{3}{|c|}{$\begin{array}{l}\text { Type of } \Psi_{\mathrm{w}}(-0.70 /-3.80 /-7.72 /-11.63 / \\
-11.53 \mathrm{MPa})\end{array}$} \\
\hline & -0.7 & -3.80 & -7.72 & -11.63 & -15.53 & $\mathrm{NaCl}$ & Glycerol & PEG 8000 \\
\hline M. circinelloides Bam1 & aab & bac & bac & $a^{*} a$ & $a^{*} a$ & abccc & $a b c^{* *}$ & bccab \\
\hline$M$. racemosus Bet1 & aab & bac & $\mathrm{cab}$ & $* * a$ & ${ }^{* *} \mathrm{a}$ & $a b c^{* * *}$ & $\mathrm{bac}^{* *}$ & aaab \\
\hline P. roqueforti Man1-3 & aab & bac & bac & $a^{*} b$ & $* * a$ & $\mathrm{abcd}^{*}$ & $\mathrm{bac}^{* *}$ & abccb \\
\hline P. chrysogenum Qpe1 & aab & $a b c$ & $a b c$ & $\mathrm{acb}$ & $b^{*} a$ & cbacd & aabc* & bbaaa \\
\hline P. discolor Maj1 & aab & $a b c$ & $a a b$ & $\mathrm{acb}$ & $b^{*} a$ & bacde & $a a b c^{*}$ & aaaba \\
\hline P. solitum Zam1 & aab & bac & $a a b$ & $\mathrm{acb}$ & $b^{*} a$ & cabcd & $\mathrm{cabd}^{*}$ & aaaba \\
\hline P. olsonii Gam1 & aab & $\mathrm{abc}$ & $\mathrm{bac}$ & $\mathrm{acb}$ & $b^{*} a$ & babbc & bbac* $^{*}$ & bbcab \\
\hline P. chermesinum Zam3 & aab & $a b c$ & bac & $\mathrm{acb}$ & $b^{*} a$ & aabcd & $\mathrm{abac}^{*}$ & aabaa \\
\hline Penicillium spp. Qpe3 & aab & bac & $\mathrm{aab}$ & $\mathrm{acb}$ & $b^{*} a$ & cabde & $\operatorname{cabd}^{*}$ & babdc \\
\hline T. amestolkiae Man1-2 & aab & $\mathrm{cab}$ & cba & *a & $* * a$ & $a b c^{* * *}$ & $a b c^{* *}$ & babbc \\
\hline M. manginii Zam2 & aaa & $\mathrm{abb}$ & aba & $b^{*} a$ & $b^{*} a$ & cabcd & $\mathrm{bab}^{* * *}$ & cbaab \\
\hline A. glaucus Man3-1 & $\mathrm{a} a \mathrm{~b}$ & $\mathrm{abc}$ & $\mathrm{a} a \mathrm{~b}$ & $* * a$ & $* * a$ & $\mathrm{bab}^{* *}$ & $\mathrm{aad}^{* *}$ & babab \\
\hline A. pseudoglaucus Man3-2 & aab & bab & $\mathrm{cab}$ & cba & $* * a$ & baab* & $\mathrm{dbac}^{*}$ & edcba \\
\hline A. varians Mah1 & bba & bac & $\mathrm{cab}$ & bca & $b^{*} a$ & abdce & $\mathrm{abcd}^{*}$ & abbaa \\
\hline G. candidum Que1 & aab & bac & $* * a$ & ${ }^{* *} \mathrm{a}$ & $* * a$ & $a b^{* * *}$ & $a b^{* * *}$ & aabcd \\
\hline
\end{tabular}

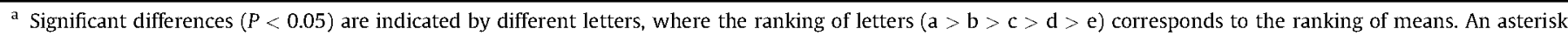
indicates that no growth was detected. 

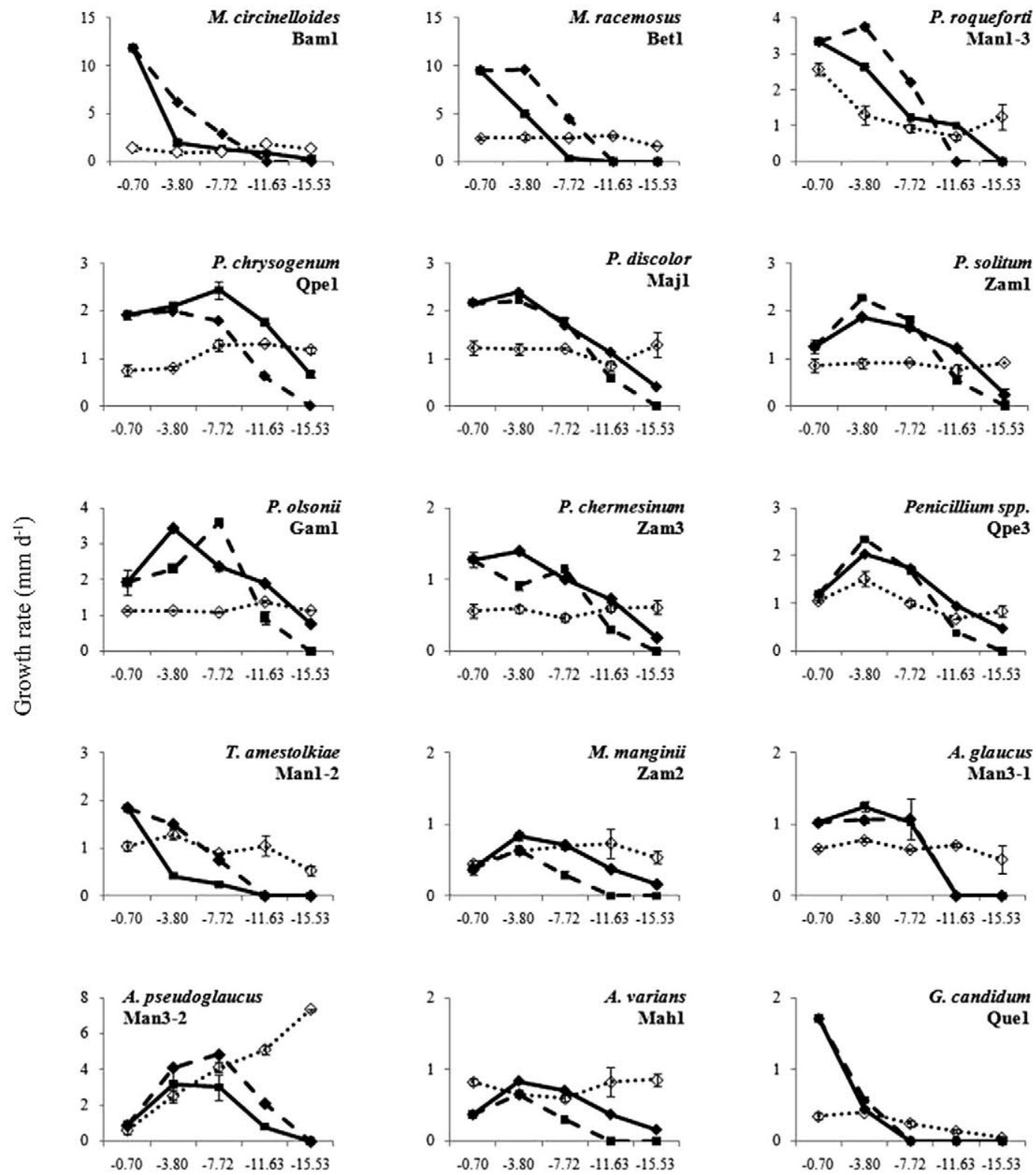

Water potential $(\mathrm{MPa})$

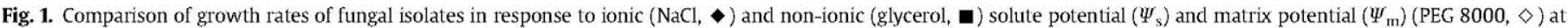
$20^{\circ} \mathrm{C}$.

conditions for growth, contrasted with the profiles of $\Psi_{\mathrm{m}}$. In this case, a more sustained growth was obtained for all the species, with the remarkable exception of $A$. pseudoglaucus, whose radial growth increased proportionally to the level of water stress imposed. It is noteworthy that all the strains were able to grow on the matrically modified medium at $-15.53 \mathrm{MPa}$ of $\Psi_{\mathrm{m}}$ and, moreover, a slight but statistically significant increase in growth rate, compared with control, was achieved at $-15.53 \mathrm{MPa}$ for the species $P$. roqueforti, P. discolor, $P$. solitum and Penicillium spp. Qpe3, and for Penicillium chrysogenum in the range of -7.72 to $-15.53 \mathrm{MPa}$.

Geotrichum candidum was the most sensitive species to osmotic water stress, being its growth indistinctively restricted by both salt and glycerol, and it was the only isolate whose growth was completely inhibited by ionic and non-ionic $\Psi_{s}$ at $-7.72 \mathrm{MPa}$. Conversely, growth profiles of the rest of the species were differentially influenced by salt and glycerol. Mucor racemosus, Mucor circinelloides, Talaromyces amestolkiae and A. pseudoglaucus were clearly more tolerant to non-ionic stress whereas $P$. chrysogenum, $M$. manginii, and $A$. varians grew faster under ionic stress. The rest of the isolates presented more tolerance to salt or glycerol depending on the range of $\Psi_{\mathrm{w}}$ considered. This was particularly evident in the case of Penicillium olsonii, whose maximum growth rate was achieved at different $\Psi_{\mathrm{w}}$ depending on the solute considered: $-3.8 \mathrm{MPa}$ with salt (ionic), and $-7.72 \mathrm{MPa}$ with glycerol (non-ionic).

\section{Discussion}

Numerous papers have dealt with identification of fungal species associated with cheese, but less is known about how 
environmental factors can affect their growth. In this work, the mycobiota associated with 19 different varieties of cheese is reported, and information about their growth profiles under different types of water stress is provided. Eight of the 15 species identified in this study belonged to species that have been frequently reported in cheese (Boutrou \& Gueguen, 2005; Hermet et al., 2012; Ropars et al., 2012). This indicates, in terms of ecology, that these species can be considered as well adapted to this food. However, 7 of the 15 species are to our knowledge reported here for the first time in cheese (Penicillium chermesinum, P. olsonii, A. varians, A. glaucus, A. pseudoglaucus, M. manginii and T. amestolkiae). It must be noted though, that identifications were based on very recent taxonomical keys and molecular data, which have resulted in splitting of some species into new ones, and the update of the name of some species. This could explain, at least partially, the presence of previously unreported species. Nevertheless, we think that the wide variety of cheeses considered in this study, most of them never explored before, could also have influenced these findings.

Penicillium was clearly the dominant genus, especially on hard cheeses. Two strains belonging to section Brevicompacta were isolated. This is a taxon comprising a number of species that have been, until recently, poorly recognised (Pitt \& Hocking, 2009). In fact, new species have been described within this section in the last few years (Frisvad, Houbrake, Popma, \& Samson, 2013; Peterson, 2004; Serra \& Peterson, 2007). One of these two isolates was identified as $P$. olsonii, a species associated with cured meats (López-Díaz, González, Moreno, \& Otero, 2002), but apparently uncommon in cheese. The other isolate (Qpe3) could not be identified, but a phylogenetic tree built on the basis of both ITS and TUB2 sequences that included all the known members from section Brevicompacta, revealed that it was most closely related to Penicillium astrolabium (data not shown). This species is associated with grapes and was firstly described by Serra and Peterson (2007). It is possible to hypothesise that Qpe3 could belong to a new species, although it would be desirable to perform more thorough taxonomic studies when new strains are available in future. For the rest of previously unreported species found in this work there is, unfortunately, little information available about their presence in foods.

The study of the influence of $\Psi_{\mathrm{w}}$ was of interest in this research because the status of water in cheese is an extremely variable parameter, which is influenced by the stage of ripening and the variety of cheese considered (Gaucel, Guillemin, \& Corrieu, 2012; Pajonk, Saurel, \& Andrieu, 2003; Saurel, Pajonk, \& Andrieu, 2004). For example, water contents might range from values as low as $30 \%$ in hard cheeses (e.g., Parmigiano) to $80 \%$ in soft cheeses (e.g., mozzarella). Besides, salt addition during manufacturing and accumulation of ionic and non-ionic low molecular compounds generated through proteolysis, have an important effect on decreasing the total water available for microorganisms growing on cheese (Duggan, Noronha, O'Riordan, \& O'Sullivan, 2008). The range of $\Psi_{\mathrm{w}}$ considered (from -0.70 to $-15.53 \mathrm{MPa}$ ) was selected according to the values typically found in cheese (Hickey, Guinee, Hou, \& Wilkinson, 2013). The results showed that whereas the decrease in water availability had a most inhibitory effect on growth of $T$. amestolkiae, $M$. circinelloides, $M$. racemosus and G. candidum, the species from genera Penicillium and Aspergillus were more tolerant to water restriction. This indicates that environmental conditions would have a huge influence on the dynamics of fungal populations while growing on cheese, favouring the growth of some species over others depending on the stage of ripening or the intrinsic characteristics of cheese. Previous reports have in fact pointed out that some mould species seem to be more widespread on certain cheeses or under particular environmental conditions. For example, G. candidum is known to be associated predominantly with soft cheeses (Boutrou \& Gueguen, 2005), as was observed in this work, and Mucor species are important spoilage agents under conditions of high humidity (Spinnler \& Leclercq-Perlat, 2007). The results obtained in this work help to explain these previous observations, although there are probably other factors involved in the distribution of fungal species which should be investigated.

A major finding was the different effect caused by ionic and nonionic water stress in some species. In cheeses, $\Psi_{\mathrm{s}}$ is affected by the salt added during manufacturing and the accumulation of ionic and non-ionic low molecular compounds generated through proteolysis. The concentration of these osmolytes may increase over time as a result of water loss during ripening. Salt-in-moisture usually ranges from 2 to 23.9 in the final product (Guinee \& Fox, 2004), but it can be even higher on the surface of cheeses that are immersed in saturated brine aqueous solutions, since a gradient is established from the rind to the core (Pajonk et al., 2003). Besides, accumulation of low molecular compounds through proteolysis is also very variable, since it depends on the activity of endogenous enzymes present in milk, the residual activity of milk coagulants (rennet) and the enzymes secreted by microbial communities (Gaucel et al., 2012). It could be then expected that the more halotolerant species, such as $P$. chrysogenum, could colonise cheeses with high-salt contents, or during the first days after brining, where more susceptible competitors would be inhibited. On the contrary, other species such as $A$. pseudoglaucus would prefer cheeses with high rate of proteolysis over those with high concentration of salt. The study of the relation between the presence of certain species and particular environmental conditions on cheese opens a vast field for further investigation.

Despite of the importance of food structure in water availability, there is a lack of information about $\Psi_{\mathrm{m}}$ in cheeses, probably because direct analysis of the structure of water in food systems is difficult to achieve (Mathlouthi, 2001). Differences in levels of water bound to cheese matrix are attributable to a large number of technological variables of the cheese making process. For example, it is known that hard cheeses have a more compact structure that restricts the water evaporation process, whereas a more open structure can be found on soft cheeses and on cheeses made with pasteurised milk (Buffa, Guamis, Saldo, \& Trujillo, 2003). Other factors, such as the application of high pressure treatments, seem to result on a stronger binding of water to the cheese matrix (Johnston \& Darcy, 2000). Our results showed, on one hand, that matric stress had less influence on variations of growth than solute stress, and on the other hand, that all the species were able to grow at the most extreme conditions of water availability, and some of them were even stimulated. Mycelial extension of other fungi such as Aspergillus flavus, Fusarium verticillioides, and of a range of basidiomycetes have previously been found to be significantly more sensitive to $\Psi_{\mathrm{m}}$ than to $\Psi_{\mathrm{s}}$ (Jurado et al., 2008). In the case of A. pseudoglaucus, growth was highly stimulated under matric stress. This ability to grow better on a substrate where water is physically constrained has also been reported in the species Eurotium repens and Eurotium herbariorum, and it could be a strategy of certain xerophilic fungi to access water in new regions (Huang, Chapman, Wilson, \& Hocking, 2009). It seems therefore clear that the use of $\Psi_{\mathrm{w}}$ as the sole predictor for microbial stability of cheese might not be valid.

The data obtained in this work could have implications in the rational management of additives used for development of cheese analogues. For example, the use of starch has been proposed to achieve a higher microbial stability in these products, since this polysaccharide can entrap water within the matrix (Duggan et al., 2008). However, our results suggest that this strategy might be ineffective for limiting fungal growth. A possible alternative to 
explore would be the use of replacement salts (magnesium, calcium or potassium), that until now has been assayed to produce healthier formulae of cheese analogues with lower sodium contents (Grummer \& Schoenfuss, 2009), which could provide an additional benefit for fungal control.

This work has identified and characterised different mould species associated with a wide range of varieties of cheese. The study of the response of these species to distinct types of water stress indicates that some manufacturing parameters on the cheese making process, such as salting, pressing or ripening, could have a determinant impact on the mycobiota of cheeses. Therefore, further research should be carried out to investigate the influence of processing variables and their interactions on the different types of $\Psi_{\mathrm{w}}$. This information would permit to identify critical points of the production process and to develop new strategies that enable to modulate fungal growth and therefore, to improve the final quality of cheeses.

\section{References}

Boutrou, R., \& Gueguen, M. (2005). Interests in Geotrichum candidum for cheese technology. International Journal of Food Microbiology, 102, 1-20.

Buffa, M., Guamis, B., Saldo, J., \& Trujillo, A. J. (2003). Changes in water binding during ripening of cheeses made from raw, pasteurized or high-pressuretreated goat milk. Lait, 83, 89-96.

Duggan, E., Noronha, N., O'Riordan, E. D., \& O'Sullivan, M. (2008). Effect of resistant starch on the water binding properties of imitation cheese. Journal of Food Engineering, 84, 108-115.

Erdogan, A., Gurses, M., \& Sert, S. (2003). Isolation of moulds capable of producing mycotoxins from blue mouldy Tulum cheeses produced in Turkey. International Journal of Food Microbiology, 85, 83-85.

Flórez, A. B., Álvarez-Martín, P., López-Díaz, T. M., \& Mayo, B. (2007). Morphotypic and molecular identification of filamentous fungi from Spanish blue-veined Cabrales cheese, and typing of Penicillium roqueforti and Geotrichum candidum isolates. International Dairy Journal, 17, 350-357.

Frisvad, J. C., Houbraken, J., Popma, S., \& Samson, R. A. (2013). Two new Penicillium species Penicillium buchwaldii and Penicillium spathulatum, producing the anticancer compound asperphenamate. FEMS Microbiology Letters, 339, 77-92.

Frisvad, J. C., \& Samson, R. A. (2004). Polyphasic taxonomy of Penicillium subgenus Penicillium. A guide to identification of food and air-borne terverticillate Penicillia and their mycotoxins. Studies in Mycology, 49, 1-173.

Gaucel, S., Guillemin, H., \& Corrieu, G. (2012). A generalised model for cheese mass loss determination during ripening. Journal of Food Engineering, 110, 109-116.

Glass, N. L., \& Donaldson, G. C. (1995). Development of primer sets designed for use with the PCR to amplify conserved genes from filamentous ascomycetes. Applied and Environmental Microbiology, 61, 1323-1330.

Grummer, J., \& Schoenfuss, T. C. (2009). Determining salt concentrations for equivalent water activity in reduced-sodium cheese by use of a model system. Journal of Dairy Science, 94, 4360-4365.

Guinee, T. P., \& Fox, P. F. (2004). Salt in cheese: physical, chemical and biologica aspects. In P. F. Fox, P. L. H. McSweeney, T. M. Cogan, \& T. P. Guinee (Eds.), General aspects: Vol. 1. Cheese chemistry, physics and microbiology (pp. 207-260). Amsterdam, The Netherlands: Elsevier Applied Science.

Hall, T. A. (1999). BioEdit: a user friendly biological sequence alignment editor and analysis program for Windows 95/98/NT. Nucleic Acids Symposium Series, 41, 95-98.

Hermet, A., Méheust, D., Mounier, J., Barbier, G., \& Jany, J. (2012). Molecular systematics in the genus Mucor with special regards to species encountered in cheese. Fungal Biology, 116, 692-705.

Hickey, D. K., Guinee, T. P., Hou, J., \& Wilkinson, M. G. (2013). Effects of variation in cheese composition and maturation on water activity in Cheddar cheese during ripening. International Dairy Journal, 30, 53-58.

Huang, Y., Chapman, B., Wilson, M., \& Hocking, A. D. (2009). Effect of agar concentration on the matric potential of glycerol agar media and the germination and growth of xerophilic and non-xerophilic fungi. International Journal of Food Microbiology, 133, 179-185.

Hubka, V., Kolaric, M., Kubatova, A., \& Peterson, S. W. (2013). Taxonomic revision of the genus Eurotium and transfer of species to Aspergillus. Mycologia, 105, 912937.

Johnston, D. E., \& Darcy, P. C. (2000). The effects of high pressure treatment on immature Mozzarella cheese. Milchwissenschaft, 55, 617-620.

Jurado, M., Marín, P., Magan, N., \& González-Jaén, M. T. (2008). Relationship between solute and matric potential stress, temperature, growth, and FUM1 gene expression in two Fusarium verticillioides strains from Spain. Applied and Environmental Microbiology, 74, 2032-2036.

Kure, C. F., \& Skaar, l. (2000). Mould growth on the Norwegian semi-hard cheeses Norvegia and Jarlsberg. International Journal of Food Microbiology, 62, 133-137.

Kure, C. F., Wasteson, Y., Brendehaug, J., \& Skaar, I. (2001). Mould contaminants on Jarlsberg and Norvegia cheese blocks from four factories. International Journal of Food Microbiology, 70, 21-27.

Larsen, M. D., \& Jensen, K. (1999). The effects of environmental conditions on the lipolytic activity of strains of Penicillium roqueforti. International journal of Food Microbiology, 46, 159-166.

Le Dréan, G., Mounier, J., Vasseur, V., Arzur, D., Habrylo, O., \& Barbier, G. (2010). Quantification of Penicillium camemberti and $P$. roqueforti mycelium by real-time PCR to assess their growth dynamics during ripening cheese. International Journal of Food Microbiology, 138, 200-207.

López-Díaz, T. M., González, C. J., Moreno, B., \& Otero, A. (2002). Effect of temperature, water activity, $\mathrm{pH}$ and some antimicrobials on the growth of Penicillium olsonii isolated from the surface of Spanish fermented meat sausage. Food Microbiology, 19, 1-7.

Lund, F., Filtenborg, O., \& Frisvad, J. C. (1995). Associated mycoflora of cheese. Food Microbiology, 12, 173-180.

Magan, N. (2007). Fungi in extreme environments, In C. P. Kubicek, \& 1. S. Druzhinia (Eds.), The Mycota. IV. Environmental and microbial relationships (pp. 85-103). Berlin, Germany: Springer Verlag.

Mathlouthi, M. (2001). Water content, water activity, water structure and the stability of foodstuffs. Food Control, 12, 409-417.

Montagna, M. T., Santacroce, M. P., Spilotros, G., Napoli, C., Minervini, F., Papa, A., et al. (2004). Investigation of fungal contamination in sheep and goat cheeses in southern Italy. Mycopathologia, 158, 245-249.

Pajonk, A. S., Saurel, R., \& Andrieu, J. (2003). Experimental study and modeling of effective $\mathrm{NaCl}$ diffusion coefficients values during Emmental cheese brining Journal of Food Engineering, 60, 307-313.

Panelli, S., Buffoni, J. N., Bonacina, C., \& Feligini, M. (2012). Identification of moulds from the Taleggio cheese environment by the use of DNA barcodes. Food Control, 28, 385-391.

Peterson, S. W. (2004). Multilocus DNA sequence analysis shows that Penicillium biourgeianum is a distinct species closely related to $P$. brevicompactum and P. olsonii. Mycological Research, 108, 434-440.

Pitt, H. I., \& Hocking, A. D. (2009). Fungi and food spoilage (3rd ed.). Dordrecht, The Netherlands: Springer.

Ropars, J., Cruaud, C., Lacoste, S., \& Dupont, J. (2012). A taxonomic and ecologic overview of cheese fungi. International Journal of Food Microbiology, 155, 199210.

Saurel, R., Pajonk, A., \& Andrieu, J. (2004). Modelling of French Emmental cheese water activity during salting and ripening periods. Journal of Food Engineering, $63,163-170$.

Scott, W. J. (1957). Water relations of food spoilage microorganisms. In E. M. Mrak, \& G. F. Stewart (Eds.), Advances in food research (Vol. VIl, pp. 83-127). New York, NY, USA: Academic Press.

Sengun, I. Y., Yaman, D. B., \& Gonul, S. A. (2008). Mycotoxins and mould contamination in cheese: a review. World Mycotoxin Journal, 1, 291-298.

Serra, R., \& Peterson, R. W. (2007). Penicillium astrolabium and Penicillium neocrassum, two new species isolated from grapes and their phylogenetic placement in the $P$. olsonii and $P$. brevicompactum clade. Mycologia, 99, 78-87.

Spinnler, H. E., \& Leclercq-Perlat, M. N. (2007). White mold cheese. In P. L. H. McSweeney (Ed.), Cheese problems solved (pp. 268-282). Cambridge, UK: Woodhead Publishing Limited.

Steuter, A. A., Mozafar, A., \& Goodin, J. R. (1981). Water potential of aqueous polyethylene glycol. Plant Physiology, 67, 64-67.

White, T. J., Burns, T., Lee, S., \& Taylor, J. W. (1990). Amplification and direct sequencing of fungal ribosomal RNA genes for phylogenetics. In M. A. Innis, D. H. Gelfand, J. J. Sninsky, \& T. J. White (Eds.), PCR protocols: A guide to methods and applications (pp. 315-322). New York, NY, USA: Academic Press Inc 